\title{
RELATO DE EXPERIÊNCIA: COMISSÃO DE COMUNICAÇÃO PARA A EXTENSÃO DA PUC-GO
}

\author{
NÚBIA DA CUNHA SimÃO ${ }^{1}$ \\ ORCID: 0000-0002-8990-9012
}

Resumo: A partir das experiências vivências na criação e constituição da Comissão de Comunicação para divulgar a extensão para alunos e professores da Pontifícia Universidade Católica de Goiás- PUC-GO, propõe-se apresentar a proposta de trabalho com acadêmicos dos cursos de Jornalismo e Publicidade e Propaganda da universidade, em atividades de divulgação das atividades da extensão, a partir da linha de trabalho do Programa de Direitos Humanos. Objetiva-se desta forma, perceber os limites que envolvem o trabalho desenvolvido e as possibilidades de crescimento na promoção da equidade social.

Palavras-chave: Educação. Direitos Humanos. Comunicação.

Abstract: Based on experiences in the creation and constitution of the Communication Commission to disseminate the extension for students and professors of the Pontifical Catholic University of Goiás - PUC-GO, it is proposed to present the proposal of work with academics of the courses of Journalism and Advertising and Propaganda of the university, in dissemination activities of extension activities, based on the work of the Human Rights Program. In this way, the objective is to understand the limits that surround the work developed and the possibilities of growth in the promotion of social equity.

Keywords: Education. Human Rights. Communication.

Resumen: A partir de las experiencias vivencias en la creación y constitución de la Comisión de Comunicación para divulgar la extensión para alumnos y profesores de la Pontificia Universidad Católica de Goiás-PUC-GO, se propone presentar la propuesta de trabajo con académicos de los cursos de Periodismo y Publicidad y Propaganda de la universidad, en

1 Mestra em Comunicação pela Faculdade de Informação e Comunicação na Universidade Federal de Goiás FIC- UFG, Especialista em Economia pela Universidade Estadual de Goiás, Jornalista graduada na Faculdade de Informação e Comunicação na Universidade Federal de Goiás FIC- UFG, Economista graduada pela Universidade Estadual de Goiás -UEG. Docente do curso de Publicidade e Propaganda da Pontifícia Universidade Católica de Goiás - PUC-GO. Professora Pesquisadora Pró-reitoria de Extensão e Pesquisa- PROPE- PUC-GO. Coordenadora do Programa de Extensão em Direitos Humanos- PUC-GO. Endereço para acessar este CV: http://lattes.cnpq. br/9575034173768476. E-mail: nubiasimao@gmail.com. 
actividades de divulgación de las actividades de la extensión, a partir de la línea de trabajo del Programa de Derechos Humanos. Objetivo de esta forma, percibir los límites que involucran el trabajo desarrollado y las posibilidades de crecimiento en la promoción de la equidad social. Palabras clave: Educación. Derechos Humanos. Comunicación.

Submetido em: 01/12/2018

Aceito em: 20/12/2018.

\section{COMUNICAÇÃO E DIREITOS HUMANOS - O PROGRAMA DE DIREITOS HUMANOS DA PUG-GO}

O Programa de Direitos Humanos- PDH faz parte da extensão da Pontifícia Universidade Católica de Goiás- PUC. O programa foi criado por acadêmicos do Centro Acadêmico do curso de Direito ainda em 1982. Compete salientar que em 2017 o programa incorporou outros três programas de extensão, que atualmente, o integram o programa como projetos, quais sejam: Programa Interdisciplinar da Mulher Estudos e Pesquisas- PIMEP, Programa de Educação e Cidadania- PEC e O Programa de Estudos e Extensão Afro-Brasileiro- Proafro.

$\mathrm{O} \mathrm{PDH}$ possui como sustentáculo o princípio da dignidade da pessoa humana, que consiste no fato de que o ser humano deve viver com dignidade, isto é, deve possuir o "mínimo vital", no que tange à vida, à saúde, à moradia, à educação, à cultura e desporto, ao transporte, ao saneamento básico, ao meio ambiente saudável, à comunicação, dentre outros.

Apesar de garantidos em documentos nacionais e internacionais, como será demonstrado, a efetivação desses princípios depende de uma tomada de posição dos sujeitos sociais, bem como de suas instituições, aqui representada pela universidade. Documentos importantes na garantia de princípios defendidos pelo PDH, fundamentais na consolidação da dignidade humana.

A Constituição Brasileira de 1988, que ficou conhecida como "Constituição Cidadã”, introduziu importantes inovações em relação à integração à nossa legislação de Tratados Internacionais firmados pelo governo brasileiro, estabelecendo no artigo $5^{\circ} \mathrm{um}$ rol de direitos fundamentais e garantias, especificamente no parágrafo $2^{\circ}$, fixando-se que os direitos e garantias expressos na Carta não excluem outros decorrentes do regime e dos princípios por ela adotados, ou dos Tratados Internacionais em que a República Federativa do Brasil seja parte.

O Supremo Tribunal Federal - STF, em decisão adotada no ano de 1977 (RTJ 83/809), declarou taxativamente que um Tratado Internacional, em que 
o Brasil é parte, tem aplicação imediata e direta no Direito interno após a sua ratificação regular pelo Congresso, não dependendo, portanto, de lei que the reproduza o conteúdo.

O STF adotou ainda posição no sentido de que Tratado Internacional tem hierarquia equivalente à de lei e, por analogia, revoga lei anterior que o contraria, o que reforça ainda mais a importância da educação em direitos humanos e do conhecimento, por meio da informação, de tais documentos e princípios, o que está delineado nos eixos de atuação do PDH da PUC Goiás.

Para se ter ideia, muitos Tratados Internacionais firmados pelo governo brasileiro já fazem parte hoje do nosso conjunto de leis. Alguns preconizam direta e objetivamente os amplos e irrestritos direitos de liberdade de expressão e de imprensa.

A Declaração Universal dos Direitos Humanos, por exemplo, em seu artigo XIX, estabelece que "Todo o homem tem direito à liberdade de opinião e expressão; este direito inclui a liberdade de, sem interferências, ter opiniões e de procurar, receber e transmitir informações e ideias por quaisquer meios, independentemente de fronteiras".

A Declaração Internacional de Chapultepec, de 1996, estabelece, em seus 10 Princípios, que: "Não há pessoas nem sociedades livres sem liberdade de expressão e de imprensa. O exercício desta não é uma concessão das autoridades; é um direito inalienável do povo, um direito de toda a sociedade, pois toda pessoa tem o direito de buscar e receber informação, expressar opiniões e divulgá-las livremente".

A Declaração Americana Sobre Direitos Humanos, também conhecida como Pacto de São José da Costa Rica, aprovada pelo Congresso Nacional e sancionada pelo presidente da República (Decreto 678/92, de 6-11-92), tem força de Lei Ordinária no Brasil. Em seu artigo XIII - Liberdade de pensamento e de expressão -, preconiza que: "Toda pessoa tem direito à liberdade de pensamento e de expressão.

Esse direito compreende a liberdade de buscar, receber e difundir informações e ideias de toda natureza, sem consideração de fronteiras, verbalmente ou por escrito, ou em forma impressa ou artística, ou por qualquer outro processo de sua escolha. Não se pode restringir o direito de expressão por vias ou meios indiretos, tais como o abuso de controles oficiais ou particulares de papel de imprensa, de frequências radioelétricas ou de equipamentos e aparelhos usados na difusão de informação, nem por quaisquer outros meios destinados a obstar 
a comunicação e a circulação de ideias e opiniões". Enfim, tanto os dispositivos da Constituição Federal, como dos Tratados Internacionais, estabelecem ampla, geral e irrestrita liberdade de expressão e de imprensa no Brasil.

O Decreto $\mathrm{n}^{\circ} 7.037$, de 21 de dezembro de 2009, que estabelece o Programa Nacional de Direitos Humanos (PNDH 3), prevê o fortalecimento de políticas públicas que favoreçam os direitos humanos, assim como a ampliação dos sistemas de informações sobre o tema. Para além dos marcos regulatórios que determinavam o caráter geral da educação em direitos humanos, expressas em documentos nacionais e internacionais dos quais o país é signatário e que foram discutidas no início do texto, o país conta, também, desde 2012, com as Diretrizes Nacionais para a Educação em Direitos Humanos.

Contudo, toda esse arcabouço normativo com suas respectivas política públicas, por si sós, não são capazes de garantir efetividade histórica aos direitos humanos. Portanto, são as práticas sociais das populações, inseridas nos múltiplos jogos de poder, isto é, na política que garantirão historicamente efetivas culturas de direitos e de paz, o que justifica os eixos de atuação do PDH da PUC Goiás (Comunicação e Direitos Humanos, Educação e Direitos Humanos e Políticas Públicas e Direitos Humanos), que tem como mote a transdisciplinaridade e a interdisciplinaridade em seus projetos, possíveis por meio do Projeto Escolas da PUC Goiás, que tem como base as necessárias transformações sociais por que passa o Brasil e o mundo.

Assim sendo o objetivo do PDH é fortalecer os direitos e garantias fundamentais, e também objetiva a tutela constitucional nos direitos humanos, além de contribuir com o processo de formação crítica e reflexiva sobre o campo dos direitos e sua garantia, aspectos que perpassam a formação acadêmica dos estudantes envolvidos nas atividades do programa e da comunidade externa à universidade. Para isso, busca articular parcerias com entidades governamentais e não governamentais, com o escopo de fortalecer a consolidação dos direitos humanos em benefício da sociedade.

\section{EIXOS DE TRABALHO}

A Os projetos desenvolvidos no PDH estão distribuídos nos seguintes eixos de atuação Comunicação e Direitos Humanos, Educação em Direitos Humanos e Políticas Públicas em Direitos Humanos. 


\section{Gestão Administrativa do programa}

O Programa de Direitos Humanos da PUC Goiás se constitui a partir de uma gestão colegiada, composta por professores e estudantes. Todo trabalho, que tem como mote os princípios e concepções discutidas no presente Projeto Pedagógico, articulados em seus eixos de atuação, são definidas em reuniões entre seus membros, em consonância com a Coordenação de Extensão (CDEX) da PUC Goiás, bem como da Pró-Reitoria de Extensão e Apoio Estudantil (Proex).

\section{FRENTES DE ATUAÇÃO POLÍTICO-PEDAGÓGICA}

\section{Eixo: Comunicação e Direitos Humanos}

Ementa: Comunicação e cidadania. Comunicação e direitos humanos. Comunicação e educação em direitos humanos. Comunicação e cidadania ativa.

Ações prevista: Produção de material audiovisual (fotografia, vídeo e áudio) e utilização das mídias sociais como canal de promoção de direitos humanos. Trabalho realizado com a participação de acadêmicos da universidade por meio do programa de voluntariado, bem como com estagiários, uma parceria com a Escola de Comunicação da PUC Goiás.

Objetivo: Articular ações e atividades de educação em direitos humanos por meio dos processos comunicativos. Elaborar e divulgar materiais em áudio, cartazes e vídeo de conteúdo em direitos humanos. Planejar, executar e divulgar campanhas educativas com viés em direitos humanos.

Justificativa: $O$ acesso à informação também configura uma necessidade política e social. Comunicar-se é, ao mesmo tempo, uma forma de interagir socialmente e de interferir nas decisões sociais. Consequentemente, negar informações, dar informações falsas ou incompletas são formas de violação de direitos humanos, uma vez que nega ao indivíduo a condição necessária à sua participação no debate público.

Destaca-se ainda que a comunicação é um dos direitos fundamentais do homem, o que está expresso na Declaração Universal dos Direitos Humanos, de 1948, em seu artigo 19. Ali pode-se ler: "[...] todo o indivíduo tem o direito à liberdade de opinião e de expressão (...) e o de procurar, receber e difundir, sem consideração de fronteiras, informações e ideias por quais meios de expressão". O direito à comunicação perpassa, também, todas as gerações de cidadania, o que refletirá diretamente na sua efetivação. 


\section{Ações permanentes}

Produção e divulgação de conteúdos nas mídias sociais

Produção de campanhas para as mídias sociais

Resgate e preservação de Memória

\section{Eixo: Educação e DH}

Ementa: Educação. Direitos Humanos. A relação entre direitos humanos e educação. Cultura da paz. Dignidade humana.

Ações Previstas: Discussões de temas relacionados aos direitos humanos por meio do Grupo de estudo. Produção de trabalhos para serem apresentados em eventos científicos de direitos humanos e áreas afins. Produção de pesquisa.

Objetivo: A Educação em Direitos Humanos, que também tem destaque nas políticas do PDH da PUC Goiás, é uma das mediações fundamentais para o acesso ao legado histórico dos direitos humanos, bem como à sua historicização atual e mesmo a universalização da dignidade humana através de ações afirmativas e práticas sociais efetivas, rumo a uma cultura dos Direitos Humanos como base para as necessárias transformações sociais no Brasil. Para tanto, é importante reconhecer a educação como um dos direitos humanos e a Educação em Direitos Humanos como parte fundamental do conjunto desses direitos.

Justificativa: Como aponta Benevides (2007, p. 335).

há pouco mais de cem anos, vivíamos, nesta terra dita de Santa Cruz, no regime da Casa Grande e Senzala. Nossos antepassados defendiam a escravidão como 'natural' (...). Somos, portanto, herdeiros de um crime hediondo, causa principal da permanência, entre nós, de uma mentalidade que desconhece ou tende a dar um conteúdo pejorativo aos Direitos Humanos.

Benevides (2007, p. 347) não poupa ao defender a importância da difusão do conhecimento acerca dos direitos humanos, que já estão garantidos legalmente, mas isso não indica que necessariamente sejam compreendidos pelo cômputo geral da população nacional:

uma vigorosa campanha de esclarecimento, nos meios de comunicação, do significado dos direitos humanos, associados á justiça social e à democracia, e um compromisso com a educação em direitos humanos, nas escolas, e em outros espaços públicos, desse já. (BENEVIDES, 2007, p. 347). 
A educação em direitos humanos, à qual se propõe o PDH da PUC Goiás, de acordo com a autora, parte de três pontos fulcrais: em primeiro lugar, ela é permanente, contínua e deve ser abrangente. Em seguida, deve-se buscar uma mudança cultural. Por fim, deve atingir corações e mentes, pois não é somente transmissão de conhecimento. Acreditando nisso, o PDH realiza atividades permanentes de visibilidade dos direitos humanos e suas violações, como colóquios, debates, mesas redondas e rodas de conversa.

\section{Ações Permanentes}

Grupo de Estudo

Roda de Conversa

Palestras, debates, encontros e seminários

\section{Projetos}

Curso de Formação Continuada - parceria com a Secretaria Municipal de Educação. Webrádio Dom Tomas Balduíno - parceria com a Secretaria Municipal de Educação.

\section{Eixo: Políticas Públicas em Direitos Humanos}

Ementa: Como componente de materialização da democracia, o PDH está ancorado na promoção dos direitos humanos, e, assim, em coerência com o PNDH3 e demais documentos legais que organiza as estratégias de operacionalização para uma participação direta e efetiva através das Relações Governamentais e com Segmentos Sociais da sociedade, dessa forma, requer o debate, a reflexão e a definição nas diversas políticas públicas e projetos sociais, desdobrando-se às responsabilidades dos sujeitos envolvidos. Assim, em conexão com o contexto socioeconômico e político contemporâneo, buscamos a construção coletiva dessas estratégias como objetivo deste eixo na luta e defesa permanente na consolidação e qualificação das relações estabelecidas.

Objetivo: Atuar na articulação e participação com Secretarias Federais, Estaduais e Municipais, bem como com os diversos Segmentos Sociais em direitos humanos, para o fortalecimento dos Direitos, contribuindo no aperfeiçoamento e demais competências relacionadas às atividades desenvolvidas em Políticas Públicas. 
Justificativa: O texto base para a construção do Plano Municipal de Direitos Humanos de Goiânia, construído no ano de 2015, a partir da I Conferência Municipal de Direitos Humanos, onde inclusive o PDH teve efetiva participação e parceria com a Secretaria Municipal de Direitos Humanos, trouxe em um dos seus eixos a Interação Democrática por meio da Participação.

Essa concepção de interação democrática construída entre os diversos órgãos do Estado e a sociedade civil trouxe consigo resultados práticos em termos de políticas públicas e avanços na interlocução de setores do poder público com toda a diversidade social, cultural, étnica e regional que caracteriza os movimentos sociais em nosso País. Avançou-se fundamentalmente na compreensão de que os Direitos Humanos constituem condição para a prevalência da dignidade humana, e que devem ser promovidos e protegidos por meio de esforço conjunto do Estado e da sociedade civil.

Portanto, o PDH acredita que a participação é a maior materialização da democracia. É no diálogo e na integração que se dá o fortalecimento dos diversos mecanismos existentes na sociedade capazes de fortalecer as discussões e o monitoramento de Políticas Públicas voltadas aos direitos humanos no Brasil.

\section{Ações Permanentes}

Acompanhamento do Pop de Rua (Comitê Goiano Intersetorial da População em Situação de Rua); Participação em fóruns, conferências, conselhos e audiências públicas sobre direitos humanos; Realização de atividades em parceria com outros programas de extensão da PUC Goiás; Participação em comissões, fóruns e conselhos de direitos humanos; Participação e promoção de atividades científicas, como eventos e congressos.

\section{A experiência na Comissão de Comunicação}

Com o objetivo geral de ampliar a visibilidade das ações da extensão junto à comunidade universitária da Pontifícia Universidade Católica de Goiás.

Sob orientação da professora e jornalista Núbia da Cunha Simão e coordenação da professora e Jornalista Denize Daudt, os acadêmicos dos cursos de Publicidade e Propaganda e Jornalismo, voluntários, bolsistas e estagiários durante o período de 2016 a 2018, produziram sos seguintes materiais, tais como arte gráfica, cartaz, folder, banner, entre outros para eventos dos programas de extensão; produção de release, atualização de mailing e contato com a imprensa; produção de spot e tv para divulgação das ações dos programas de 
extensão; Produção de fotos, vídeos e textos para alimentar as redes sociais; Produção e edição de programas de rádio;

\section{A produção dos acadêmicos}

Imacem 1. Cartaz para o eVento: Comunicação, Saúde e Direitos humanos, Quais LIMITES ÉTICOS, PROMOVIDO PELO PDH.

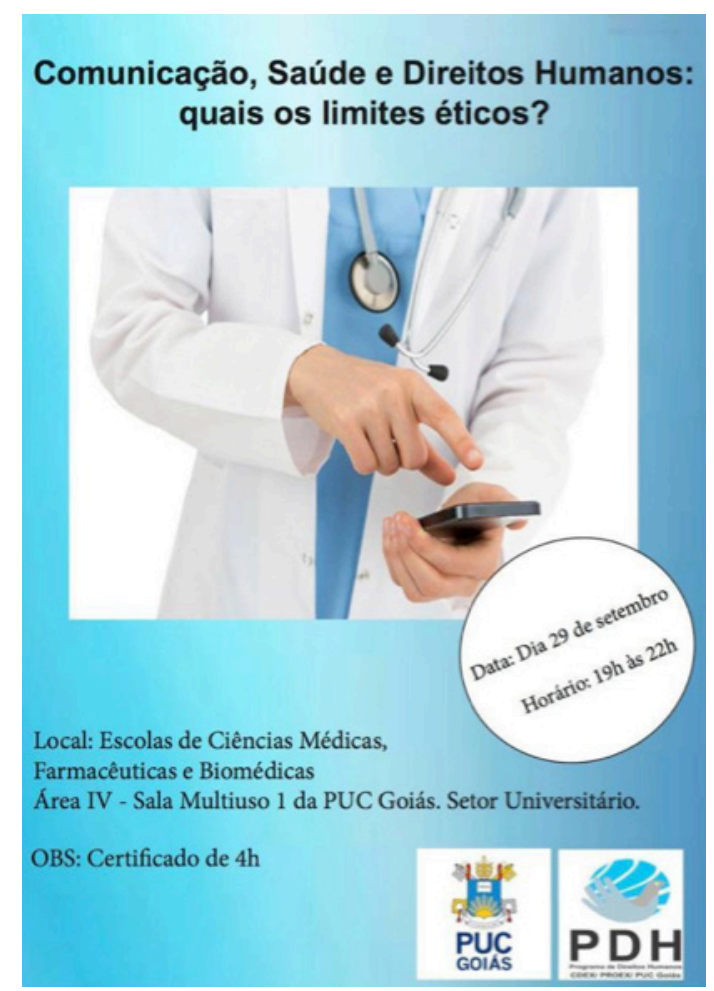

Fonte: Produzido pela voluntária Ana Carolina Marquez Rosa, do curso de Publicidade e propacanda DA PUC-CO.

Imacem 2. CARTAZ PARA O EVENTO: SeminÁRIO do GRUPo de Estudos do PIMEP

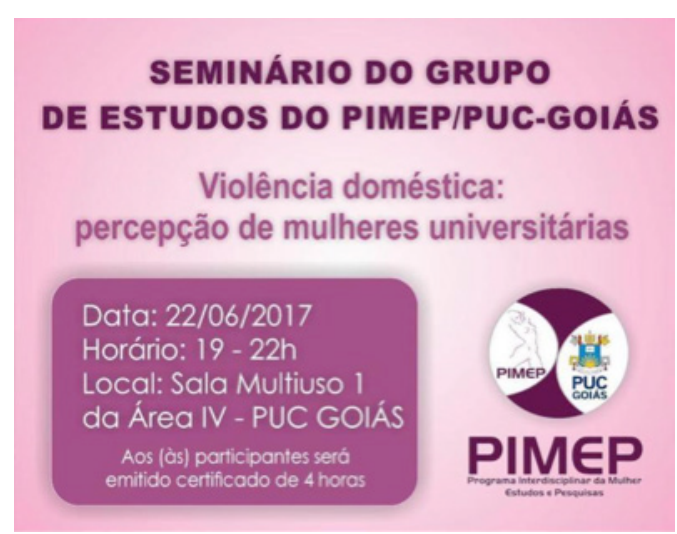

Fonte: Produzido Pelo Voluntário Matheus Ávila, do CURSo de Publicidade e propacanda da PUC-CO. 
Imacem 3. CARTAZ PARA O EVENTO: VII ColóQUio de EduCAÇÃo e CidAdania: CRIANÇAS E ADOLESCENTES COMO SUJEITOS DE DIREITOS, PROMOVIDO PELO PEC.

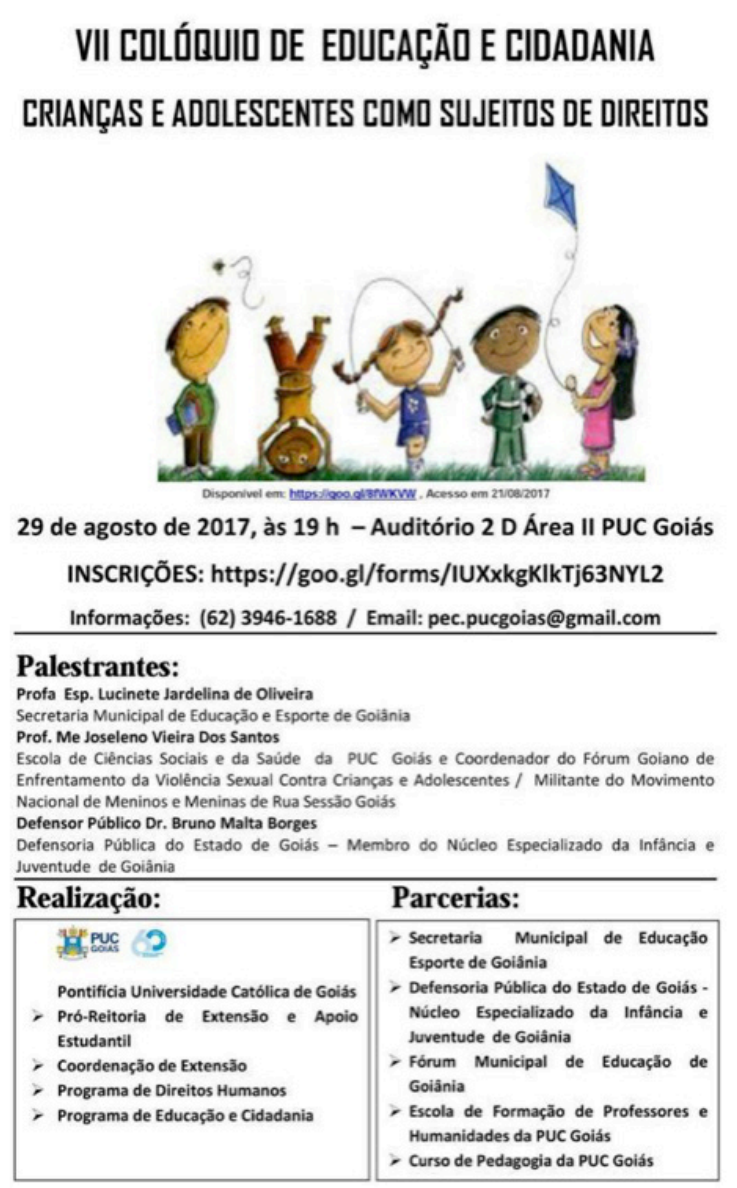

Fonte: Produzido pelo voluntário Gabriel Ávila, do curso de Publicidade e propacanda da PUC-CO.

\section{AUTOAVALIAÇÃO}

No que tange à questão do atendimento das necessidades de Comunicação e Direitos Humanos, parte-se do pressuposto que a comunicação em Direitos Humanos é fundamental para a formação do cidadão e o combate à violência, em qualquer sociedade. O Programa atendeu a sua proposta de atuação em Direitos Humanos com a formação de voluntários para produção de materiais gráficos, audiovisuais e textos para divulgação das atividades da extensão.

Quanto às possibilidades formativas, os acadêmicos relataram que ao participarem das discussões sobre Direitos Humanos foi possível conhecer um universo de comunidades e pessoas que abriram novas possibilidades de criação e consolidação de percepções diferenciadas do ser humano e de concepção da divulgação da promoção de direitos humanos. 
No entanto, durante a orientação dos acadêmicos e referentes às produções foram vivenciados diversos limites. A falta de disciplinas que faziam referência a Direitos Humanos na matriz curricular do curso de Publicidade e Propaganda, e após discussões com o grupo de professores, a matriz do curso foi modificada para 2018, incluindo disciplinas como Propaganda Social e Comunicação Institucional. Outro limite é a falta de recursos tecnológicos, tais como câmeras para fotografia e filmagens, microfones e equipamentos de captação de som, como microfones. Então, a produção de materiais audiovisuais dependia do uso dos celulares dos acadêmicos.

Assim, embora tivesse vivenciado um limite, o programa ofereceu à universidade feedback necessário para mudança na matriz curricular do curso de Publicidade e Propaganda e a discussão com o colegiado do grupo sobre as limitações na formação do curso de Publicidade e a produção de comunicação para a promoção dos direitos humanos. Outro limite foi a falta de financiamento, alguns acadêmicos sentiam-se desestimulados e explicavam que precisavam receber recursos financeiros para prosseguir no trabalho, pois passavam por dificuldades financeiras para prosseguir no curso.

\section{REFERÊNCIAS}

ABREU, Sergio Augusto; SOBRINHO, Lima Florêncio. Desdobramentos recentes no sistema ONU de Direitos Humanos: o novo Conselho de Direitos Humanos e a atuação do Brasil. In: GIOVANETTI, Andrea (org.). 60 anos da Declaração Universal dos Direitos Humanos: contribuições do Brasil. Brasília: FUNAG, 2009.

BENEVIDES, Maria Victoria. Direitos Humanos: Desafios para o século XXI. SILVEIRA, Rosa Maria Godoy, et. al. (Orgs). Educação em Direitos Humanos: fundamentos teóricos-metodológicos. João Pessoa: Editora Universitária, 2007.

BRASIL. Plano Nacional de Educação em Direitos Humanos, 2008. Disponível em: portal.mec.gov.br. Acesso em: 20 out. 2015.

GOIÂS. PONTIFÍCIA UNIVERSIDADE CATÓLICA DE GOIÁS. Relatório de Atividades de 2003 do Programa de Direitos Humanos: Uma Experiência Interdisciplinar. Goiânia, 2003.

MARTINS, Estevão C. de Rezende. Cultura e Poder. 2. ed. São Paulo: Saraiva, 2007.

SANTOS, Boaventura Sousa. Reconhecer para libertar: os caminhos do cosmopolitismo cultural. Rio de Janeiro: Civilização Brasileira, 2003.

PAULA, Maria Ana de. Relatório das Atividades do Serviço Social no Escritório Modelo e Programa de Direitos Humanos, no Período de Janeiro a Junho/86. Goiânia, 1986. 